\title{
ZINA MENURUT PANDANGAN AL QUR'AN (Kajian Tafsir Tematik Tentang Ayat-Ayat Zina)
}

\author{
Oleh: \\ Achmad $^{1}$ \\ Email: achmad.rosul@gmail.com
}

\begin{abstract}
Adultery is to have intercourse between men and women without a legitimate marriage bond. Al-Qur'an talks about adultery in three letters, namely: first, al-Qur'an, al-Isra verse (32). Secondly, al-Qur'an al-Nur verse (2) and verse (3). Third, Al-Furqan verse 68. The first verse (QS. Al-Isra 'verse 32) contains a prohibition on approaching adultery. The second (QS.An-nur verse 2-3) contains the law for the perpetrators of adultery and the prohibition of marrying it, and the third verse QS. Al-Furqan verse (68) contains the reply of the perpetrators of adultery later in the sight of Allah. In Islam the word zina includes zina muhshan and ghairu muhshan. Limitation of adultery which must be had is 12 (twelve), namely: 1) Mukallaf, 2) male, 3) including all the hasyafah (penis tip), 4) original sex, 5) the genitals are still integrated with the person, 6) inserting clear sex in women, 7) law is prohibited to include it is indeed in the dzatiyah, 8) the law of prohibition arises from reality, 9) there must be no syubhat aborted on had, 10) the sex must be interested in character, 11) perpetrator zina must fulfill Islamic laws, and 12) the perpetrator must understand the prohibition of adultery.
\end{abstract}

Key words: zina, interpretation, al-Qur'an

\section{Pendahuluan}

Islam merupakan agama universal yang di dalamnya terdapat ajaran syari'at yang meliputi tauhid, ibadah, dan akhlak. Ajaran tauhid sangat erat kaitannya dengan keimanan sementara ibadah dan akhlak merupakan pengejawantahan dari ajaran tauhid, khususnya ketika seorang hamba percaya kepada Allah maka dengan otomatis ia pun harus tunduk pada seluruh aturan yang diperintahkan oleh Allah, baik perintah yang berupa melaksanakan atau perintah untuk menjahui larangan-Nya .

${ }^{1}$ Dosen Prodi Hukum Pidana Islam STAI Syaichona Moh. Cholil Bangkalan 
Perbuatan zina salah satu dimensi yang senantiasa mewarnai perbuatan manusia dimana perbuatan tersebut masuk dalam kategori akhlak yang tidak terpuji, sehingga dalam Islam lahan bagi kajian tentang perzinahan masuk dalam kategori pada akhlak, karena perbuatan tersebut bersangkut paut dengan etis. Pebuatan zina merupakan perbuatan yang sangat tidak etis dan tidak terhormat. Hal tersebut terbukti dari adanya ketidaksenangan seseorang atau kebencian ketika anak atau istrinya di zinahi oleh orang lain maupun dia sendiri adalah seorang pezina.

Al-Syaikh al-Imam Muhammad al-Nawawi al-Jawi al-Banteni, dalam kitab Nihayah Al-Zain, mengatakan bagi orang merdeka-orang yang bukan budak sahaya-yang melakukan zina maka wajib kepada penguasa untuk menjilid (mendera) sebagai hukumannya sebanyak seratus kali dan diasingkan selama satu tahun. ${ }^{2}$ Pernyataan beliau ini membuktikan bahwa perbuatan zina ini adalah perbuatan yang sangat tercela yang bisa mencoreng nama keluarga sampai ke anak turunannya, sesuai dengan pernyataan beliau harus diasingkan selama satu tahun sehingga nama keluarga tersebut bisa harum kembali di mata masyarakat.

\section{Ayat Ayat Tentang Zina}

Ayat-ayat yang menerangkan zina dalam al-Qur'an terdapat dalam tiga surat, yaitu: surat al-Isra' ayat (32), surat an-Nur ayat (2) dan (3), dan surat al-Furqon ayat (68). Surat yang pertama (al-Isra') diturunkan di Makkah (ayat Makkiyah) surat yang kedua (an-Nur) diturunkan di Madinah (ayat Madaniyah) dan surat yang ketiga (al-Furqon) diturunkan di Makkah (ayat Makkiyah). ${ }^{3}$

Ayat pertama yang menjelaskan tentang zina adalah QS, Al- Isra'ayat $32^{4}$

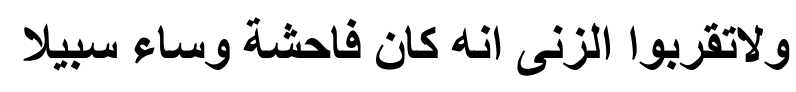

${ }^{2}$ Muhammad bin Umar bin Ali Nawawi Al Banteni Al Jawi. Nihayah Al Zain (Semarang:Toha Putra: t.t.), hlm. 327.

${ }^{4}$ Salim Bahreisy dan Abdullah Bahreisy. Terjemah Al Qur'an Al Hakim. (Surabaya: Sahabat Ilmu, 2001) 
Artinya: Dan janganlah kamu mendekati zina, sesungguhnya zina itu adalah suatu pekerjaan yang keji dan jalan yang tidak baik.(QS. alIsra':32)

Ayat kedua yang menjelaskan tentang zina adalah QS surat alNurayat 2 dan 3

\section{الزانية والزاني فاجلدوا كل واحد مائة جلدة ولاتاوخذكم بهما راعفة في دين الله ان كتنم تؤمنون بالله واليوم الاخر وليشهد عذابهما طائفة من الموعمنين}

Artinya: Perempuan yang berzina dan laki-laki yang berzina, maka deralah tiap-tiap satu dari keduanya dengan seratus kali deraan. Dan janganlah kamu belas kasihan kepada keduanya didalam menjalankan (ketentuan) agama Allah yaitu jika kamu beriman kepada Allah dan hari akhir. Dan hendaklah (dalam melaksanakan) hukuman mereka disaksikan oleh sekumpulan orang-orang yang beriman (QS.An-Nur:2)

\section{الزاني لا ينكح الازانية اومشركة والزانية لاينكها الازان اومشرك وحرم ذلك على الموعمنين}

Artinya: "Laki-laki yang berzina tidak mengawini melainkan perempuan yang berzina, atau perempuan yang musyrik dan perempuan yang berzina tidak dikawini melainkan oleh laki-laki yang berzina atau lakilaki musyrik dan yang demikian itu diharamkan atas orang-orang yang beriman.(QS. An-Nur:3)

Ayat ke tiga yang menjelaskan tentang zina adalah QS, Al-Furgon Ayat 68




Artinya: Dan orang-orang yang tidak menyembah Tuhan yang lain beserta Allah dan tidak membunuh jiwa yang diharamkan Allah (membunuhnya) kecuali dengan (alasan) yang benar, dan tidak berzina, barang siapa melakukan yang demikian itu, niscaya dia akan mendapat (pembalasan) dosa (nya).( QS, Al-Furqon: 68)

\section{Asbab Al-Nuzul (Sebab Turunnya Ayat Zina)}

Selain dijelaskan ayat-ayat yang menerangkan zina maka penulis menganggap penting untuk menjelaskan sebab-sebab turunnya ayat tersebut agar bisa dipahami kandungan isinya secara luas.

Ayat-ayat yang menerangkan tentang zina ini diturunkan melalui tiga tahapan. Ayat yang pertama yang menerangkan tentang zina adalah surat al-Isra' ayat (32), kedua surat al-Nur ayat (2 dan 3) dan ketiga surat al-Furqan ayat (68). Berikut ini akan dijelaskan tahapan serta sebab turunnya ayat-ayat tersebut, sekalipun tidak semuanya ditemukan sebab nuzulnya.

Pertama, ayat yang diturunkan adalah ayat 32 surat al-Isra', ayat ini hanya menyatakan larangan untuk mendekati zina karena itu pekerjaan yang keji. Ayat ini diturunkan dalam kasus seorang pemuda. Pada suatu hari ada seorang pemuda yang meminta izin kepada Rasulallah SAW untuk melakukan zina dengan seorang perempuan, maka turunlah ayat ini sebagai larangan berzina.

Kedua, ayat yang diturunkan adalah ayat 2 dan 3 surat an-Nur. Ayat (2) ini menyatakan perempuan dan laki laki yang melakukan zina akan dijilid (cambuk) sebanyak seratus kali. Sedangkan ayat yang ke 3 menyatakan bahwa laki-laki pezina tidak boleh nikah kecuali pada perempuan pezina juga atau musyrikah (perempuan musyrik) dan perempuan pezina tidak boleh nikah kecuali pada lelaki pezina juga atau musyrik (laki laki musyrik).

Ayat ini diturunkan dalam kasus Mazid. Dalam penuturan Amr Ibn Syuaib bahwa suatu ketika Mazid lelaki dari al-Anbar yang membawa barang dagangannya ke Makkah bertemu dengan teman wanitanya, anak seorang pezina. Mazid meminta izin kepada Nabi Muhammad untuk menikahinya akan tetapi Nabi tidak langsung menjawab, setelah turun 
ayat ini beliau berkata "Mazid kamu jangan menikahi wanita itu" (HR.Abu Dawud). ${ }^{5}$

Dalam riwayat lain dijelaskan bahwa sebab turunnya ayat di atas adalah dahulu ada seorang laki laki bernama Murtadz al-Ghonawi yang ditugaskan membawa tawanan dari Makkah ke Madinah. Dia membawa anak seorang penjajah seks, dan anak itu mengajak Murtadz untuk berhubungan (zina). Saat sampai di Madinah, Murtadz bertanya kepada Rasulallah, lalu kemudian turunlah surat al-Nur ayat (2) dan al-Isra' ayat (32).

Ketiga, ayat yang di turunkan adalah ayat (68) surat al-Furqan. Ayat ini menyatakan bahwa termasuk orang yang diakui seorang hamba yang dicintai oleh Allah adalah orang yang tidak pernah menyekutukan Allah, tidak pernah membunuh kecuali dengan hak, dan tidak pernah melakukan zina. Dalam riwayat Al-Bukhori dan lain-lain, yang bersumber dari Ibnu Abbas, bahwa ketika turun ayat di atas kaum musyrikin berkata "kami telah membunuh orang tanpa alasan yang hak, telah menyeru kepada tuhan selain Allah, dan juga telah melakukan zina" maka turunlah ayat selanjutnya yang menunjukkan jalan untuk bertaubat kepada Allah.

\section{Penafsiran dan Penjelasan Ayat-Ayat Zina}

Zina dalam al-Qur'an dibicarakan melalui tiga tahapan. Tahap yang pertama sekedar larangan untuk mendekati dan melakukan zina, yaitu (QS. Al-Isra' Ayat 32). Kemudian disusul dengan tindakan bagi yang melakukan zina dan larangan mengawini pezina, (QS. al-Nur Ayat 2-3). Selanjutnya pada tahap ketiga menjelaskan tentang balasan di sisi Allah bagi pelaku zina yaitu QS. al-Furqan Ayat 68.

Di dalam ayat ke 32 surat al-Isra' Allah memulainya dengan larangan untuk mendekati zina. Allah Swt sengaja memulai firmannya dengan kalimat (لاتقربو الزنىى) jangan kamu mendekati zina, bukan kalimat jangan kamu melakukan zina, larangan mendekati zina dalam konteks ayat tersebut lebih mengena dan mendalam (baligh) dari pada larangan melakukan zina, karena larangan mendekati itu mencakup

${ }^{5}$ Nasiri, “Tafsir Tematik” di https://brainly.co.id. dan diakses 07 Agustus 2018 
muqoddimat al-zina (pemanasan yang mengarah pada zina) seperti: memegang, mengecup, melihat, meraba dan lain-lain dari hal- hal yang bisa menjerumuskan kepada zina.

Dari penjelasan di atas, maka bisa dipahami bahwa larangan mendekati lebih baligh dari pada larangan melakukan zina karena mendekatinya saja sudah dilarang apalagi melakukannya6.

Dalam ayat di atas, Allah menentukan larangan zina bukan liwath padahal liwath (menggauli lewat jalan belakang) itu lebih parah dan lebih besar dosanya dari pada zina, sebab zina itu sudah berjalan di kalangan Arab, sedangkan liwath banyak di lakukan oleh kaumnya Nabi Luth yang sejatinya senang sesama laki.7

Selanjutnya ayat ke 2 surat al-Nur, Allah menjelaskan bahwa setiap laki-laki yang berzina atau perempuan yang berzina akan mendapatkan hukuman jilid (cambuk) sebanyak seratus kali dengan memakai cambuk. Hal demikian ini disyariatkan sebagai efek jera bagi pelakunya. Dalam hal memberi efek jera, maka dilarang untuk belas kasihan pada keduanya dalam menjalankan perintah Allah. Selain itu, Allah juga melarang untuk mengurangi siksaan pada pelakunya hanya karena kasihan, bahkan harus tegas dalam menegakkan agama Allah. Imam Mujahid berkata "Jangan mengosongkan had-had Allah dan jangan meninggalkan untuk menegakkannya hanya karena kasian". 8

Ayat di atas, Allah mendahulukan kata muannats (perempuan) dari pada mudzakkar (laki-laki) dalam had zina karena syahwat (keinginan) perempuan untuk berzina itu lebih kuat dan lebih banyak dari pada lakilaki. Hal ini berbeda dengan ayat yang menerangkan hadnya sariqoh (mencuri), (والسارق والسارقة), di situ Allah mendahulukan mudzakkar dari pada muannats. Perbedaan ini dikarenakan kasus dalam pencurian itu timbul dari keberanian dan kuat dan banyak dimiliki oleh orang laki-laki .9

\footnotetext{
${ }^{6}$ Muhammad Ali Al-Sabuni, ShofahAl-Tafasir fi Tafsir Al Qur'an Al -K arim, Juz II (Beirut: Dar al-Fikr, 2001). hlm.146.

${ }^{7}$ Syekh Ahmad Ibni Muhammad al Shawi al Mishri, Hasyiah Al shawi Ala Tafsir Jalalain Juz III (Beirut: Dar Fikr, 2005), hlm .318. 298

${ }^{8}$ Muhammad Ali al-Shabuni. ShofahAl-Tafasir fi Tafsir Al Qur'an Al-Karim, hlm

${ }^{9}$ Syekh Ahmad Ibni Muhammad Al Shawi Al Mishri, Hasyiah Al Shawi, Hlm.25
} 
Dalam pelaksanaan hukuman, dianjurkan untuk menghadirkan segolongan dari orang-orang yang beriman, agar supaya lebih menimbulkan efek jera bagi pelakunya.

Dalam Ayat ke 3 surat al-Nur, Allah menjelaskan larangan untuk menikahi laki-laki pezina atau perempuan pezina, yaitu laki-laki pezina tidak boleh menikahi perempuan yang terjaga ('afifah) dan mulia, begitu juga perempuan pezina tidak boleh menikahi laki laki terjaga dan mulia, bahkan carilah sesama pezina atau di bawahnya. Demikian ini disebabkan jiwa yang suci enggan untuk menikahi seorang pezina dan fasik. Iman AlFakhr mengatakan "sebaik-baiknya ucapan yang bisa di ambil intisari dalam tafsiran ini adalah bahwa orang laki-laki fasik dan jelek yang pekerjaannya zina dan selalu fasik itu biasanya tidak senang untuk menikahi perempuan sholihah, bahkan ia senang untuk mencari perempuan yang fasik dan jelek juga begitu juga perempuan fasiqoh dan jelek ia cenderung untuk mencari sesamanya10." Sedangkan kepada orang orang mukmin haram hukumnya menikahi pezina karena pekerjaannya yang sangat menjijikkan dan membahayakan pada badan dan akhirnya bisa mengakibatkan kematian.

Ayat yang terakhir yaitu ayat ke 68 surat al-Furqan. Allah menjelaskan bahwa orang yang betul-betul dicintai oleh Allah adalah orang yang tidak pernah menyekutukan Allah dengan yang lain, bahkan mereka mengesakan Allah dengan ikhlas menjunjung tinggi agama Allah dan tidak pernah membunuh kecuali dengan alasan yang benar, yaitu mereka tidak pernah membunuh kecuali pada orang-orang yang memang hak untuk dibunuh, seperti kafir setelah beriman dan melakukan zina setelah berkeluaga. ${ }^{11}$

\section{Macam-Macam Zina dalam Islam}

Zina adalah melakukan hubungan badan antara laki-laki dan perempuan tanpa adanya suatu ikatan pernikahan yang sah. Dalam syariat Islam pelaku perzinahan dibedakan menjadi 2 (dua), yaitu pezina muhsan dan ghairu muhsan. Pezina muhsan adalah orang yang melakukan

\footnotetext{
${ }^{10}$ Ibid Hlm 298

${ }^{11}$ Muhammad Ali Asshabuni,ShofahAl-Tafasir fi Tafsir Al Qur'an Al -Karim ,Juz II (Beirut: Dar al-Fikr, 2001), hlm 339.
} 
perzinahan dan dia sudah baligh, berakal sehat, merdeka (bukan budak), dan telah punya pasangan yang sah. Sedangkan ghairu muhsan adalah orang yang belum menikah-belum mempunyai pasangan yang sahnamun dia baligh, berakal sehat, dan merdeka. ${ }^{12}$

Hukuman bagi pelaku zina muhsan adalah harus dirajam (dilempar) dengan memakai batu yang sedang, tidak boleh memakai batu yang kecil (kerikil) agar tidak terlalu lama dalam menyiksa dan juga tidak boleh memakai batu yang besar agar tidak terlalu mempercepat mati. Sedangkan hukuman bagi pelaku zina ghairu muhsan adalah dicambuk sebanyak seratus kali dan diasingkan selama satu tahun di tempat yang agak jauh, minimal jarak perjalanan yang bisa mengqasar salat.

Adapun syarat ihsan ada 4 (empat), yaitu: (1) harus baligh sehingga tidak termasuk muhsan ketika dilakukan oleh anak kecil. (2) Harus berakal sehat sehingga tidak termasuk muhsan ketika dilakukan oleh orang gila.13(3) Harus merdeka, sehingga tidak termasuk muhsan ketika dilakukan oleh buda' mub'ad (budak yang separuhnya sudah merdeka), mukatab (budak yang sudah mulai menyicil untuk jadi merdeka), dan ummul walad (budak anak dari hasil hubungan majikan dengan budak perempuan). (4) Harus di lakukan oleh orang Islam atau dzimmi dalam keadaan punya istri dari hasil perkawinan yang sah, sehingga tidak dikatakan muhsan apabila tidak melalui perkawinan yang sah. ${ }^{14}$

\section{Batasan Zina yang Mewajibkan Had (Hukuman Pasti)}

Perbuat zina berakibat hukum had. Had adalah hukuman pasti yang sudah ada ketentuannya dalam al-Qur'an dan atau hadits-hadits Nabi Muhammad SAW. Hukuman ini bisa berupa dipukul dengan rotan-yang biasa disebut dengan jilid - bisa juga dilempar dengan batu sebesar gepalan

\footnotetext{
${ }^{12}$ Muhammad Ibrahim al-Bayjuri, Hasyiyah al-Bayjuri, Juz II, hlm 234.

13 Anak kecil dan orang gila jika melakukan perzinahan, keduanya cukup diberikan pendidikan dengan hal-hal yang bisa membuat keduanya jera dan tidak mengulangi perzinahan lagi.

${ }^{14}$ Syeh Ibrahim Al Bajuri Hasyiah Syeh Ibrahim Al Bajuri Ala Syarhi Al Allamah Ibnu Qasim Al ghuzzy. (Dar Al-Abidin, Surabaya, t,th) Hlm, 232.
} 
tangan-yang biasa disebut dengan rajam-serta bisa juga ditambah dengan diasingkan ke tempat pengasingan. ${ }^{15}$

Dalam Islam, tidak semua orang yang melaukan hubungan badan dengan orang lain itu wajib untuk di-had, karena itu ulama' masih mengklasifikasi dan menetapkan syarat-syarat tertentu bagi mereka. Berikut ini adalah syarat-syarat perbuatan zina yang mewajibkan untuk had. Ulama' membagi syarat tersebut menjadi 12 bagian.

1. Mukallaf (orang yang sudah cakap hukum), bila yang melakukan tidak mukallaf maka tidak wajid di-had.

2. Jelas jenis kelaminnya, sehingga tidaklah wajib di-had bila dilakukan khuntsa musykil (banci punya dua kelamin).

3. Memasukkan semua hasyafahnya (alat kelaminnya), tidak wajib had bila hanya sebagian yang masuk.

4. Kelamin asli, sehingga tidaklah wajib had bila memasukkan kelamin buatan yang dijejerkan dengan yang asli, karena masih diragukan antara yang buatan dan yang asli.

5. Kelaminnya masih menyatu dengan orangnya, sehingga tidaklah wajibdi had bila kelaminnya putus dari pemiliknya.

6. Memasukkan kelaminnya pada perempuan yang jelas, sehingga tidaklah wajib had bila dimasukkan pada kelaminnya khuntsa musykil (banci berkelamin dua), karena dia masih mencakup laki-laki dan kelamin satunya adalah tambahan.

7. Hukum keharaman memasukkannya adalah memang ada pada dzatnya, sehingga tidaklah wajib had bila keharamannya tidak terdapat pada dzatnya, seperti menggauli istrinya dalam keadaan haid atau dalam keadaan puasa atau lewat jalan belakang.

8. Hukum keharamannya timbul dari kenyataannya, sehingga tidaklah wajib had bila menggauli istrinya dengan menduga orang lain.

9. Harus tidak terdapat syubhat (keserupaan atau kehkhilafan) yang menggugurkan pada had, sehingga tidaklah wajib had bila menggauli istrinya yang masih melakukan iddah atau budaknya yang sudah kawin, karena syubhat dalam kepemilikan.

${ }^{15}$ Muhammad Ibrahim al-Bayjuri, Hasyiyah al-Bayjuri. Juz I (Beirut: Darul Kutub al-Ilmiah, 1998). Hlm. 243. 
10. Kelaminnya harus disyahwati (minati) secara tabiat, sehingga tidaklah wajib had bila menggauli orang yang mati atau menggauli hewan, karena farjinya (kelaminnya) tidak diminati secara tabiat, bahkan hukumannya hanya dita'zir.

11. Pelaku zina harus menetapi hukum Islam, sehingga tidaklah wajib had bila yang melakukannya orang kafir harbi sekalipun mu'ahad.

12. Pelaku harus mengerti tentang keharaman zina, sehingga tidaklah wajib had bila yang melakukannya orang bodoh dengan catatan apabila dia baru masuk Islam atau hidup jauh dari ulama'.16

\section{Hikmah Keharaman Zina}

Dalam syari'at Islam, perbuatan zina akan membahayakan pribadi seseorang, keluarga dan juga warga serta masyarakat umum. Allah Swt akan menghukum pelaku zina dengan begitu berat, baik di saat masih hidup di dunia maupun di saat dia sudah mati terlebih pada hari kiamat nanti.

Oleh karena itu, Islam sangat melarang perbuatan zina tersebut. Ada beberapa hikmah dibalik larangan dari perbuatan zina ini. Berikut ini penulis uraikan beberapa hikmah larangan berzina:

1. Agar terhindar dari segala bentuk tersebarnya kejahatan zina. Hal ini dikarenakan akibat dari perzinahan akan memunculkan banyak permasalahan. Misalnya terjadinya penyiksaan dan bahkan pembunuhan akibat dari perasaan cemburu dan juga rasa marah oleh pasangan hidupnya yang sah.

2. Untuk melindungi kehormatan perempuan. Melindungi kehormatan seorang perempuan biar tidak jadi praktik jual beli perempuan, sebab Islam merupakan agama yang amat memuliakan manusia, baik yang berjenis kelamin laki-laki ataupun perempuan. Larangan perbuatan zina menggambarkan salah satu wujud penghormatan untuk kalangan perempuan. Terbukti dalam sejarah, sejak Islam hadir, perempuan jadi makhluk yang mulia dan juga senantiasa dilindungi, sebab pada era jahiliyah banyak perempuan yang diperlakukan secara tidak

\footnotetext{
${ }^{16}$ Muhammad bin Umar bin Ali Nawawi Al Banteni Al Jawi, Nihayah Al Zain
} (Toha Putra Semarang :t th.) Hlm 347. 
manusiawi bahkan mereka pula dikira bagaikan barang dan juga pemuas pria. Selain itu, dahulu jika seorang mempunyai anak perempuan akan menggambarkan aib untuk suatu keluarga, sehingga anak perempuan dikubur hidup-hidup di masa tersebut.

3. Untuk menghindari pencampuran nasab. Dengan adanya larangan zina ini, maka nasab seorang anak akan jelas dan tidak akan campur, sehingga dalam hal perwalian nikah dan pembagian warisan juga akan mudah dan tidak rumit dalam pelaksanaannya.

4. Agar terhindar dari banyaknya anak yang terlantar. Perbuatan zina jika sampai hamil maka akan lahirlah anak hasil perbuatan zina tersebut dan tentunya anak hasil perzinahan ini akan terlantar. Selain itu, larangan zina pula bermanfaat buat melindungi bayi-bayi yang dibunuh oleh ibunya seorang diri di saat dalam kandungan (aborsi).

5. Melindungi keutuhan dan juga ketenteraman dalam rumah tangga. Dalam ikatan suami istri, bila salah satunya melaksanakan perbuatan zina tentu saja hendak menghancurkan keutuhan rumah tangga. Tidak hanya itu, di dalam Islam apabila salah satu dari suami ataupun istri melaksanakan zina hingga itu mengisyarakat kalau orang tersebut tidak mampu melindungi kehormatan dan juga harus diceraikan.

6. Setimpal dengan fitrah manusia. Seseorang manusia yang memiliki rasa ghira/cemburu terhadap kehormatannya, dia tidak akan rela apabila orang yang dicintainya jadi benda yang diperjualbelikan dan juga diperuntukkan bagaikan pemuas nafsu. Dia tidak akan rela bunda yang dicintainya, istri, ataupun gadis dan juga kerabat perempuannya dizinahi oleh orang lain.

7. Menghindari penyebaran penyakit menular. Larangan berzina pula bertujuan supaya manusia bebas dari bermacam penyakit meluas serupa HIV/AIDS. Penyakit tersebut menggambarkan hukuman dari Allah atas perbuatan keji yang sudah mereka jalani.

\section{Simpulan}

Zina dibicarakan oleh al-Qur'an melalui tiga tahapan.Tahap yang pertama sekedar larangan untuk mendekati dan melakukan zina, yaitu 
(QS. al-Isra' ayat 32). Kemudian disusul dengan tindakan bagi yang melakukan zina dan larangan mengawini pezina (QS. al-Nur ayat 2-3). Selanjutnya pada tahap ketiga menjelaskan tentang balasan di sisi Allah bagi pelaku zina (QS.Al- Furqan Ayat 68).

Pelaku zina di dalam Islam dibagi menjadi dua bagian, pertama muhsan dan yang kedua ghairu muhsan. Ada beberapa syarat dalam penerapan hukuman bagi para pelaku zina, yaitu antara lain: mukallaf, pelakunya jelas, memasukkan alat kelamin, kelamin asli, tidak akan kesamaran dalam perbuatannya, dan lain sebagainya. Selain itu, Allah memberikan hikmah di dalam larangan ini, antara lain: terhindar dari penyakit, meminimalisir kejahatan, menjaga kehormatan perempuan, meluruskan nasab anak agar tidak terhindar dari percampuran nasab, dan lain sebagainya.

\section{DAFTAR PUSTAKA}

Al-Sabuni, 'Ali. 2000. Tafsir Ayat al-Ahkam. Beirut: Dar al-Kutub al-Ilmiah.

Hamid, Nasr. 1993. Mafhum al-Nas Dirasah fi 'Ulum al-Qur'an. Mesir: alHai'ah al-Misriyah li al-Kitabah.

Ibnu, Amr, Sulaiman. 1994. Al-Futuhat al-Ilahiyah. Kairo: Dar Fikr.

Kathir, Isma'il, Ibnu. 1997. Tafsir al-Qur'an al-Karim li Ibn al-Kathir. Beirut: Dar al-Kutub). 
Qattan, Mannan. 1982. Mabahith fi 'Ulum al-Qur'an. Kairo: Isa al-Halabi.

Qurtubi, Abi Abdillah. 1993. Al-Jami' li Ahkam al-Qur'an. Bairut: Dar alKutub.

Sa'id, Muhammad. 2002. al-Mu'jam al-Mufahras li al-Alfaz al-Qur'an. Beirut: Dar al-Ma'rifah).

Sawi, Ahmad. 1993. Hashiyah al-'Allamah al-Sawi 'Ala Tafsir al-Jalalain. Beirut: Dar al-Fikr.

Shata, Abu Bakar Muhammad. t.t. I'anat al-Talibin. Semarang: Taha Putra.

Shihab, Quraish. 2004. Tafsir al-Misbah, Pesan Kesan dan Keserasian alQur'an. Jakarta: Lentera Hati.

Suhendi, Hendi. 2002. Fikih Muamalah. Jakarta: Raja Grafindo Persada.

Suyuti, Imam. 1951. al-Itqan fi Ulum al-Qur'an. Kairo: al-Halabi.

Tabary, Abi Jakfar Muhammad bin al-Jarir. Tafsir al-Tabary. Beirut: Dar alKutub.

Zarkashi, Imam. 1998. al-Burhan fi 'Ulum al-Qur'an. Kairo: Isa al-Halabi.

Zuhayli, Wabah 1999. al-Tafsir al-Munir fi al-'Aqidah wa al-Shari'ah wa alManhaj. Beirut: Dar al-Fikr al-Mu'asir. 